\title{
CURVAS DOSE-RESPOSTA EM ESPÉCIES DE PLANTAS DANINHAS COM O USO DO HERBICIDA GLYPHOSATE(1)
}

\author{
ANDRÉ LUIZ DE SOUZA LACERDA ${ }^{(2)}$; RICARDO VICTORIA FILHO ${ }^{(3)}$
}

\begin{abstract}
RESUMO
Com o objetivo de verificar a resposta de diferentes espécies de plantas daninhas ao herbicida glyphosate, foi desenvolvido em câmara de crescimento um experimento inteiramente casualizado, com cinco repetições no Departamento de Produção Vegetal da ESALQ/USP. Para isso, foram estudadas seis espécies de plantas daninhas: Bidens pilosa L., Tridax procumbens L., Digitaria insularis (L). Fedde, Spermacoce latifolia Aubl., Ipomoea grandifolia L. e Commelina benghalensis L. Utilizou-se o herbicida glyphosate, inibidor da enzima EPSPs, com doses em escalas de 0,$0 ; 11,3 ; 22,5 ; 45 ; 90 ; 180 ; 360 ; 720$ e 1.440 g.ha ${ }^{-1}$ i.a. A elaboração das curvas dose-resposta foi feita pelo ajuste da equação dos dados coletados de biomassa verde utilizando o modelo $\log$-logístico: $\mathrm{Y}=\mathrm{C}+\mathrm{D}-\mathrm{C} / 1+\operatorname{Exp}\{\mathbf{b}[\log (\mathbf{x})-\log (\mathbf{R C} 50)]\}$, calculado por modelo estatístico não linear dos dados pelo programa estatístico SAS. Após a determinação das curvas dose-resposta nas espécies acima citadas concluiu-se que Bidens pilosa foi considerada a planta daninha mais suscetível ao herbicida glyphosate, pois apresentou menor RC50 (31,86 g.ha ${ }^{-1}$ i.a.). As espécies Tridax procumbens, Digitaria insularis, Spermacoce latifolia, Ipomoea grandifolia, Commelina benghalensis obtiveram RC50 de 58,40; 128,$50 ; 250,44 ; 615,49$ e $>1.440$ g.ha ${ }^{-1}$ i.a. respectivamente. Portanto, a quantidade necessária de herbicida para reduzir em $50 \%$ a biomassa verde foi de 1,$83 ; 4,03 ; 7,86 ; 32$ e $>359,56$ vezes maior em relação à Bidens pilosa respectivamente.
\end{abstract}

Palavras-chave: resposta de doses, Spermacoce latifolia, Tridax procumbens, Commelina benghalensis.

\section{ABSTRACT \\ DOSE-RESPONSE CURVES IN WEED SPECIES WITH THE USE OF HERBICIDE GLYPHOSATE}

With the objective of veryfing the response of different doses in species of weeds by herbicide glyphosate, an experiment was conducted in growth chamber in a completetly randomized design with three repetitions, in the Department of Vegetable Production at ESALQ/USP. For that, were chosen six species of weeds: Bidens pilosa L., Tridax procumbens L., Digitaria insularis (L.) Feed, Spermacoce latifolia Aubl., Ipomoea grandifolia $\mathrm{L}$. and Commelina benghalensis $\mathrm{L}$. The herbicide glyphosate, inhibitor of the enzyme EPSPs, was used at rate $0.0 ; 11.3 ; 22.5 ; 45 ; 90 ; 180 ; 360 ; 720$ and 1440 g.ha $^{-1}$ a.i. Curves of dose-response were made by the adjustment of the equation of the collected data of green biomass using the log-logistic model: Y $=\mathrm{C}+\mathrm{D}-\mathrm{C} / 1+\operatorname{Exp}\{\mathbf{b}[\log (\mathbf{x})-\log (\mathbf{R C} 50)]\}$, calculated by the no linear statistical model through the SAS statistical program. After the determination of the dose-response curves for the species mentioned above the Bidens pilosa was considered the most susceptible weed to glyphosate, showing the houvest RC50 (31.86 g.ha ${ }^{-1}$ a.i.). The species Tridax procumbens, Digitaria insularis, Spermacoce latifolia, Ipomoea grandifolia and Commelina benghalensis obtained RC50 equal to 58.40; 128.50; 250.44; 615.49 and > 1440.00 g.ha $^{-1}$ a.i., respectively, what means that the necessary amount of herbicide to reduce in $50 \%$ the green biomass was $1.83 ; 4.03 ; 7.86 ; 19.31$ and $>359.56$ times higher in relation the Bidens pilosa.

Key words: response doses, Spermacoce latifolia, Tridax procumbens, Commelina benghalensis.

(1) Recebido para publicação em 2 de junho de 2003 e aceito em 12 de dezembro de 2003.

( $\left.{ }^{2}\right)$ Doutor em Agronomia, Departamento de Produção Vegetal, Escola Superior de Agricultura “Luiz de Queiroz/USP, Caixa Postal 9, 13417-950 Piracicaba (SP). E-mail: alslacer@esalq.usp.br

$\left({ }^{3}\right)$ Departamento de Produção Vegetal - ESALQ/USP, Piracicaba (SP). E-mail: rvictori@esalq.usp.br 


\section{INTRODUÇÃO}

Diversos autores têm utilizado e recomendado a curva dose-resposta para determinar a suscetibilidade ou resistência de plantas daninhas aos herbicidas aplicados em diversas culturas (STREIBIG et al. 1993, Friensen et al. 1993, Madsen e Jensen 1995, PONCHIO et al. 1997 e Hall et al. 1998).

Existem diversos métodos para obter a curva dose-resposta, porém o mais utilizado na Europa pelos pesquisadores em Ciências das Plantas Daninhas, segundo Christoffoleti (1999) é o modelo matemático log-logístico proposto por SEEFELDT et al. (1995).

O parâmetro RC50 é citado, pelo autor, como a principal vantagem do modelo, pois determina a quantidade necessária do herbicida para inibir $50 \%$ do crescimento e/ou desenvolvimento da espécie em estudo, possibilitando indicar o biótipo resistente e o nível de resistência, pela relação dos RC50 suscetível/RC50 resistente.

Biótipos podem apresentar níveis diversos de resistência. Considera-se que ocorre resistência quando um biótipo resiste a duas vezes ou mais a dose que normalmente controla os biótipos suscetíveis. Em alguns casos, essa resistência é quebrada com aumento de dose, em outros não.

Em casos extremos, têm sido constatada resistências a doses até 100 vezes maiores que a dose normalmente eficiente (KISSMANN, 2003).

O RC50 tem sido usado não somente nos estudos de caracterização de resistência de biótipos de plantas daninhas, mas também na determinação da seletividade de variedades resistentes ou tolerantes, comparando-as com variedades não melhoradas para essa característica. É o caso de plantas geneticamente modificadas que receberam genes para suportar doses de determinados herbicidas, facilitando assim, o controle e manejo de plantas daninhas.

A Monsanto foi primeira empresa a inserir o gene da bactéria Agrobacterium tumefaciens na cultura de soja, tornando-a tolerante ao herbicida glyphosate. Em seguida, vieram outras empresas que também desenvolveram culturas geneticamente modificadas, como exemplo, plantas de milho tolerante ao glufosinato de amônio.

O objetivo do presente trabalho foi determinar a curva dose-resposta nas espécies de plantas daninhas Bidens pilosa L., Tridax procumbens L., Digitaria insularis (L.) Feed, Spermacoce latifolia Aubl., Ipomoea grandifolia L. e Commelina benghalensis L.com a aplicação do herbicida glyphosate.

\section{MATERIAL E MÉTODOS}

O experimento foi desenvolvido no Departamento de Produção Vegetal da Escola Superior de Agricultura "Luiz de Queiroz", Universidade de São Paulo, Piracicaba (SP). O delineamento experimental utilizado foi inteiramente casualizado, com três repetições. As sementes foram obtidas na Agro Cosmos Ltda., empresa produtora de sementes de plantas daninhas, as quais foram semeadas sobre substrato (Plantmax ${ }^{\circledR}$ ) contido em caixas plásticas de dimensão $50 \times 30 \mathrm{~cm}$ e acondicionadas em câmara de crescimento da marca Conviron, Modelo GR48, regulada à temperatura de $28{ }^{\circ} \mathrm{C}$, umidade relativa do ar de $80 \%$ e 14 horas de luz com intensidade luminosa de 370 $\mu$ moles $/ \mathrm{m}^{2} / \mathrm{s}$ ou 30 Klux. No estádio de desenvolvimento de um par de folhas definitivas foram transplantadas em vasos com 9,5 cm de diâmetro, contendo furos no fundo para permitir a percolação do excesso de água, substrato (Plantmax ${ }^{\circledR}$ ) e densidade de três plantas/vaso. As espécies foram submetidas aos tratamentos quando estavam no estádio de desenvolvimento de dois a três pares de folhas definitivas em I. grandifolia (corda-de-viola), B. pilosa (picão-preto), T. procumbens (erva-de-touro) e S. latifolia (erva-quente) e quatro folhas em $C$. benghalensis (trapoeraba) e D. insularis (capim-amargoso).

O herbicida utilizado foi o glyphosate (sal de isopropilamina), inibidor da enzima 5-enolpiruvilshiquimato-3-fosfato sintase (EPSPs), responsável pela formação de aminoácidos aromáticos (fenilalanina, triptofano e tirosina), na formulação CS com 360 g.L. $\mathrm{L}^{-1}$ de equivalente ácido e doses de 0,$0 ; 11,3 ; 22,5 ; 45 ; 90$; 180; 360; 720 e 1.440 g.ha ${ }^{-1}$ i.a. em uma câmara de aspersão (Figura 1) especialmente construída para aplicação de herbicidas, no Departamento de Produção Vegetal da ESALQ/USP.

Foi utilizado ponta Teejet XR 110.02, volume de calda equivalente a $300{\mathrm{~L} . h a^{-1}}^{-1}$ e pressão constante de 279,2 Kpa. Após a aplicação, os vasos foram acondicionados em casa de vegetação, sem irrigação, por 24 horas para garantir a absorção do herbicida e, após esse período, irrigados diariamente para manter a umidade do substrato próxima à capacidade de campo.

As avaliações ocorreram 21 dias após aplicação dos herbicidas, sendo as plantas daninhas coletadas por corte efetuado com tesoura, próximo ao colo das plantas, identificadas, pesadas imediatamente em balança de precisão de $0,01 \mathrm{~g}$ para obtenção da biomassa verde e, em seguida, colocadas em saco de papel e transportadas para câmara de circulação de ar forçado, regulada a $\pm 70{ }^{\circ} \mathrm{C}$ por quatro dias para obtenção da biomassa seca. 


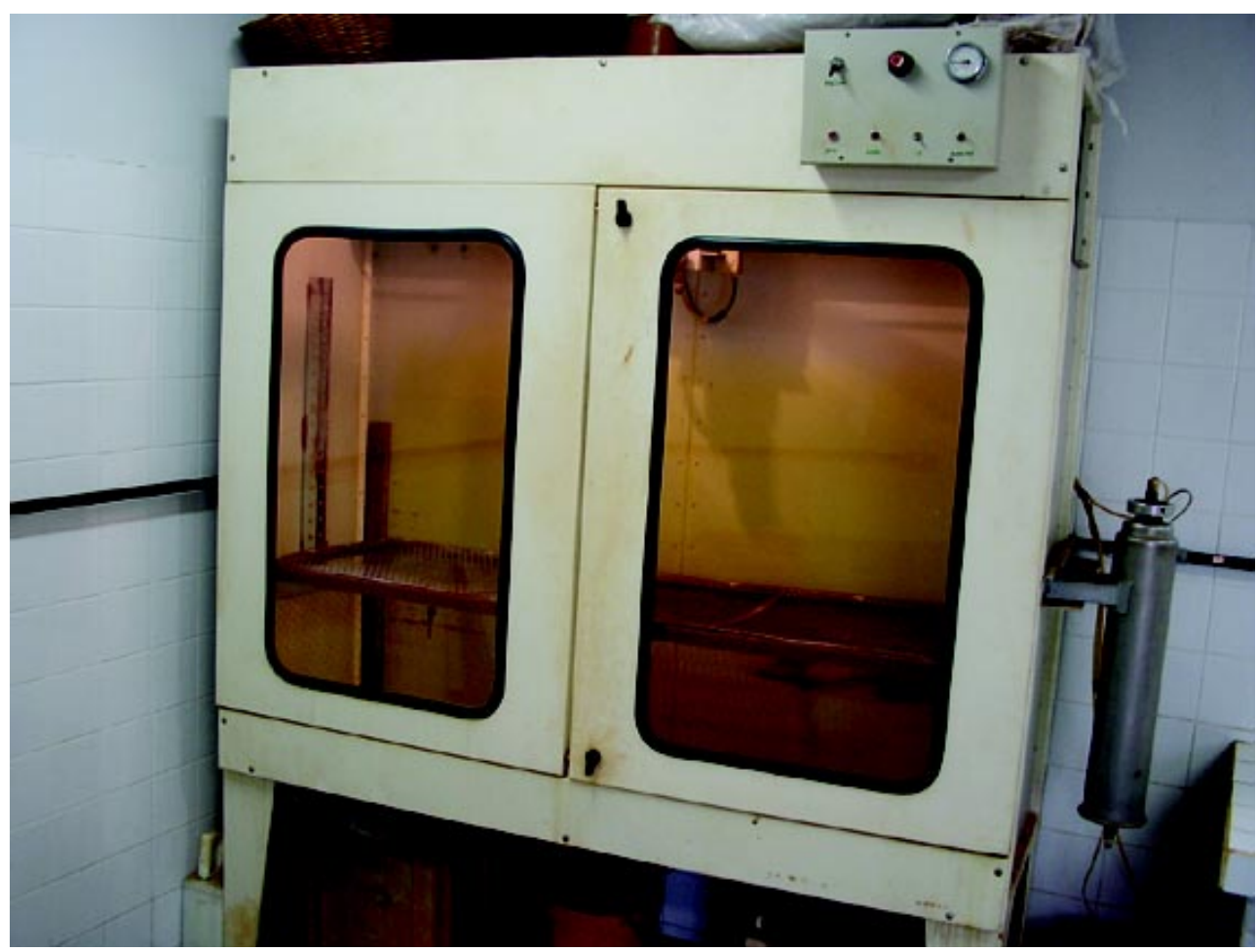

Figura 1. Câmara de aspersão onde foram feitas as aplicações de glyphosate.

Os resultados foram submetidos à análise da variância do programa estatístico SAS (Statistical Analysis System), com o objetivo de verificar se as doses do herbicida glyphosate acusaram efeito significativo na resposta das plantas daninhas. Para isso, foram utilizados somente os dados da variável biomassa verde, pois a biomassa seca apresentou grande variabilidade, não apresentando bom ajuste da curva dose-resposta. A determinação da curva doseresposta obtida pelo modelo matemático log-logístico, proposto por SEEFELDT (1995), é a seguinte:

$$
\mathrm{Y}=\mathrm{C}+\mathrm{D}-\mathrm{C} / 1+\operatorname{Exp}\{\mathrm{b}[\log (\mathrm{x})-\log (\mathrm{RC} 50)]\}
$$

Em que: $Y=$ resposta da planta; $X=$ dose do herbicida; $\mathrm{D}=$ limite superior da curva; $\mathrm{C}=$ limite inferior da curva; $\mathrm{b}=$ declividade da curva; $\mathrm{RC} 50=$ dose necessária para reduzir $50 \%$ do crescimento da planta daninha em relação à testemunha. Os valores dos parâmetros D, C e RC50 foram inicialmente colocados como tentativa de obter o ajuste da curva.

\section{RESULTADOS E DISCUSSÃO}

Na Tabela 1, a análise da variância mostra que houve efeito significativo a $1 \%$ de probabilidade, pelo teste F, das doses de glyphosate utilizadas para verificação do crescimento de B. pilosa, T. procumbens, D. insularis, S. latifolia, I. grandifolia e C. benghalensis pela redução ou inibição da biomassa verde de cada espécie, em relação à testemunha, conforme descrito em Material e Métodos.

Procedeu-se a análise da regressão não linear dos dados utilizando o modelo log-logístico proposto por SEEFELDT et al. (1995), e realizada pelo programa estatístico SAS (Statistical Analysis System), conforme procedimento no Anexo I, com o objetivo de obter os parâmetros necessários para confeccionar as curvas dose-resposta e determinar os indicadores estatísticos de precisão dos dados originais coletados.

Os parâmetros da equação encontram-se na Tabela 2; verificou-se que os valores de $\mathrm{R}^{2}$ são próximos de 1 , indicando alto ajuste da equação em relação aos dados originais coletados. Os valores de C, nas espécies S. latifolia, I. grandifolia e $C$. benghalensis foram negativos $(-0,38 ;-0,76$ e $-18,44)$ respectivamente.

Na prática, não existe porcentagem de redução de crescimento negativo, porém Christoffoleti (1999) considera esse resultado normal, desde que o intervalo de confiança do valor de $C$ é suficientemente grande, que inclua valores maiores, menores ou iguais a zero. 
Tabela 1. Análise da variância do efeito das doses do herbicida glyphosate no crescimento de Bidens pilosa, Tridax procumbens, Digitaria insularis, Spermacoce latifolia, Ipomoea grandifolia e Commelina benghalensis em função da redução de biomassa verde em relação a testemunha

\begin{tabular}{lcccc}
\hline Espécies & GL & QM & F & CV \% \\
\hline B. pilosa & 8 & 25,63 & $29,49^{* *}$ & 17,6 \\
T. procumbens & 8 & 4,39 & $28,40^{* *}$ & 19,2 \\
D. insularis & 8 & 8,72 & $29,04^{* *}$ & 23,0 \\
S. latifólia & 8 & 2,57 & $64,69^{* *}$ & 12,9 \\
I. grandifolia & 8 & 1,61 & $14,15^{* *}$ & 14,3 \\
C. benghalensis & 8 & 36,47 & $12,84^{* *}$ & 17,4 \\
\hline
\end{tabular}

** Diferença significativa a $1 \%$ de probabilidade pelo teste $\mathrm{F}$.

Tabela 2. Parâmetros das equações das curvas dose-resposta em Bidens pilosa, Tridax procumbens, Digitaria insularis, Spermacoce latifolia, Ipomoea grandifolia e Commelina benghalensis

\begin{tabular}{lccccccc}
\hline Espécies & $\mathrm{D}$ & Inferior & $\mathrm{C}$ & Superior & RC50 & $\mathrm{b}$ & $\mathrm{R}^{2}$ \\
\hline T. procumbens & 3,55 & $-7,28$ & 0,45 & 3,34 & 58,40 & 3,98 & 0,92 \\
C. benghalensis & 14,67 & $-18,40$ & $-18,44$ & $-18,40$ & $>1.440,00$ & 3,37 & 0,85 \\
S. latifolia & 2,52 & $-1,19$ & $-0,38$ & 0,42 & 250,44 & 2,38 & 0,96 \\
D. insularis & 3,96 & $-1,36$ & 0,36 & 0,46 & 128,50 & 4,07 & 0,93 \\
B. pilosa & 8,67 & $-0,39$ & 0,15 & 1,08 & 31,86 & 5,58 & 0,93 \\
I. grandifolia & 3,53 & $-2,99$ & $-1,97$ & 0,87 & 615,49 & 1,40 & 0,86 \\
\hline
\end{tabular}

O comportamento das curvas dose-resposta nas espécies de plantas daninhas testadas com a aplicação das doses de glyphosate encontra-se na Figura 2. Verifica-se pelas curvas que as espécies têm comportamentos diferentes entre si e às doses do herbicida glyphosate. A espécie B. pilosa mostrou maior sensibilidade, pois seu RC50 foi de 31,86 g.ha ${ }^{-1}$ i.a., sendo o menor valor encontrado, seguido de $T$. procumbens RC50 igual a 58,40 g.ha ${ }^{-1}$ i.a. Com apenas 90 g.ha ${ }^{-1}$ i.a. de glyphosate aplicados em B. pilosa conseguiu-se importante redução de sua biomassa verde, ocasionando valores acima de $90 \%$, enquanto as outras espécies necessitaram de doses maiores para conseguirem o mesmo resultado.

Foi o caso de D. insularis e S. latifolia que necessitam doses acima de 720 g.ha ${ }^{-1}$ i.a. para atingir patamar próximo de $90 \%$. Essas espécies apresentaram sensibilidade intermediária às doses de glyphosate e redução de crescimento expressivo na dose de 1.440 g.ha- ${ }^{1}$ i.a.

I. grandifolia e C. benghalensis não apresentaram, porém, os mesmos resultados de resposta às doses aplicadas de glyphosate. Verificou-se que $I$. grandifolia apresentou curva dose-resposta semelhante a C. benghalensis, porém mais sensível, devido ao glyphosate ter ocasionado resposta na menor dose aplicada. Por outro lado, a espécie $C$. benghalensis respondeu somente a partir de 180 g.ha ${ }^{-1}$ i.a. Também ficou difícil determinar qual a dose que proporcionaria uma redução de fitomassa satisfatória nessa espécie, pois as doses utilizadas não foram suficientes para atingir o nível de $50 \%$ de redução na câmara de crescimento.

A classificação de plantas daninhas mais sensíveis à aplicação de glyphosate, utilizando o parâmetro RC50, ajustadas pela equação curvas doseresposta propostas por SEEFELDT et al (1995) e a relação do RC50 das espécies mais resistentes com a espécie de planta daninha mais suscetível, encontram-se na Tabela 3. A planta mais sensível ao glyphosate foi $B$. pilosa com menor RC50 $(=31,86)$. Isso significa que foi necessário dose de 31,86 g.ha ${ }^{-1}$ i.a. do herbicida para proporcionar $50 \%$ de redução de sua biomassa verde. T. procumbens, $D$. insularis, S. latifolia, I. grandifolia, C. benghalensis obtiveram RC50 igual a 58,$40 ; 128,50 ; 250,44 ; 615,49$ e $>1.440,00$ g.ha $^{-1}$ i.a. respectivamente. 


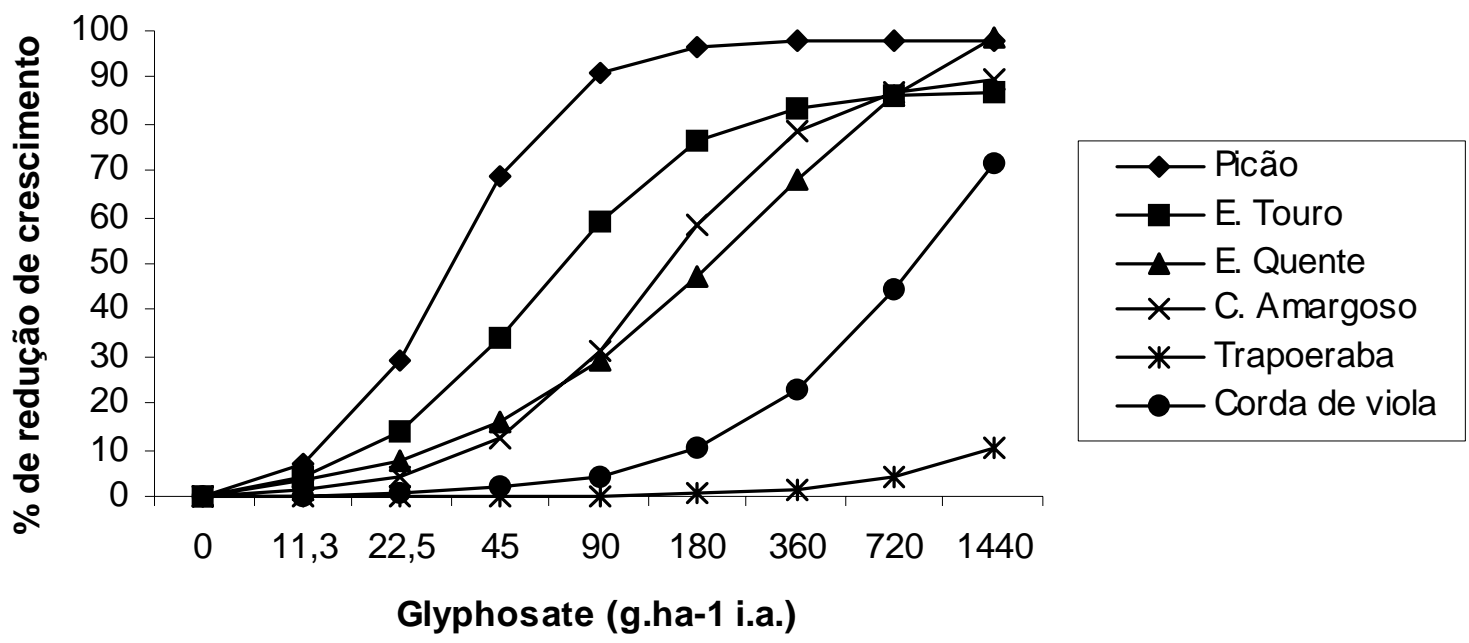

Figura 2. Curvas dose-resposta nas espécies I. grandifolia (corda-de-viola), B. pilosa (picão-preto), T. procumbens (ervade-touro) e S. latifolia (erva-quente), C. benghalensis (trapoeraba) e D. insularis (capim-amargoso) tratadas com glyphosate nas doses 0,$0 ; 11,3 ; 22,5 ; 45 ; 90 ; 180 ; 360 ; 720$ e 1.440 g.ha $^{-1}$ i.a.

Tabela 3. Classificação das espécies de plantas daninhas sensíveis ao glyphosate pelo parâmetro RC50 ajustado pela curva dose-resposta e relação do RC50 das espécies mais resistentes com a mais suscetível

\begin{tabular}{lrr}
\hline Espécies & RC50 & Relação RC50 \\
\hline Bidens pilosa & 31,86 & 1,00 \\
Tridax procumbens & 58,40 & 1,83 \\
Digitaria insularis & 128,50 & 4,03 \\
Spermacoce latifolia & 250,44 & 7,86 \\
Ipomoea grandifolia & 615,49 & 19,31 \\
Commelina benghalensis & $>1.440,00$ & $>359,56$ \\
\hline
\end{tabular}

Sendo B. pilosa a planta daninha mais suscetível ao glyphosate, foi considerada como unidade referencial, e os valores de RC50 das demais espécies, divididos por ela.

Portanto, a classificação de suscetibilidade ou resistência ao glyphosate pela divisão do RC50 de $T$. procumbens, D. insularis, S. latifolia, I. grandifolia, C. benghalensis com o RC50 de B. pilosa mostrou ser necessário quantidade de doses 1,$83 ; 4,03 ; 7,86 ; 19,31$ e $>359,56$ vezes maior que a espécie suscetível para, respectivamente, poder reduzir $50 \%$ de biomassa verde.

\section{CONCLUSÕES}

1. A espécie B. pilosa foi considerada a planta daninha suscetível ao herbicida glyphosate, sendo a espécie de menor RC50 (31,86 g.ha-1 i.a.).

2. As espécies T. procumbens, D. insularis, $S$. latifolia, I. grandifolia, C. benghalensis apresentaram RC50 igual a 58,40; 128,$50 ; 250,44 ; 615,49$ e $>1.440,00$ g.ha ${ }^{-1}$ i.a., significando que a quantidade necessária de herbicida para reduzir ou inibir em $50 \%$ a biomassa verde foi de 1,$83 ; 4,03 ; 7,86 ; 19,31$ e $>359,56$ vezes maior em relação à espécie $B$. pilosa respectivamente. 


\section{ANEXO I}

PROCEDIMENTOS UTILIZADOS NO PROGRAMA ESTATÍSTICO SAS, PARA OBTER OS PARÂMETROS

DA EQUAÇÃO, ELABORAR AS CURVAS DOSE-RESPOSTA E ANÁLISE ESTATÍSTICA

DATA TRIDAX;

INPUT DOSE REP GREENWGT;

IF DOSE > O THEN LOGDOSE = LOG(DOSE);

ELSE LOGDOSE = LOG(11.3/4);

CARDS;

$$
\begin{array}{ccc}
1440 & 1 & 0.13 \\
1440 & 2 & 0.17 \\
1440 & 3 & 0.13 \\
\cdot & \cdot & \cdot \\
\cdot & \cdot & \cdot \\
. & \cdot & \cdot \\
0 & 1 & 3.14 \\
0 & 2 & 3.16 \\
0 & 3 & 3.25
\end{array}
$$

RUN;

PROC PLOT DATA=TRIDAX;

PLOT GREENWGT*LOGDOSE;

RUN;

PROC GLM DATA=TRIDAX;

CLASS DOSE;

MODEL GREENWGT=DOSE

/SS1 SS2 SOLUTION;

RUN;

PROC NLIN DATA=TRIDAX;

PARAMETERS

$\mathrm{D}=3.34$

$\mathrm{C}=0.13$

$\mathrm{RC} 50=1.95$

$\mathrm{b}=2$

;

IF DOSE $=0$ THEN PREDICT $=\mathrm{D}$;

ELSE PREDICT $=\mathrm{C}+(\mathrm{D}-\mathrm{C}) /$

$\left(1+\operatorname{EXP}\left(b^{*}(\right.\right.$ LOGDOSE-LOG(RC50) $\left.\left.)\right)\right)$;

MODEL GREENWGT=PREDICT;

RUN;

; 


\section{REFERÊNCIAS}

CHRISTOFFOLETI, P.J. Resistência de plantas daninhas aos herbicidas inibidores da acetolactato sintase e acetil coenzima A carboxilase. 1999. 211f. Tese (Livre Docência) - Escola Superior de Agricultura "Luiz de Queiroz", Universidade de São Paulo, Piracicaba.

FRIENSEN, L.F; MORRISON, I.N.; RASHID, A; DEVINE, M.D. Response of a chlorosulfuron resistant biotype of Kochia scoparia to sulfonylurea and alternative herbicides. Weed Science, Champaign, v.41, n.1, p.100-106. 1993.

HALL, S.E.; SAUNDERS, J.W.; PENNER, D. Semidominant nature of monogenic sulfonylureia herbicide resistance in sugarbeet (Beta vulgaris). Weed Techonology, Champaign, v.10, n.4, p.936-942, 1996.

KISSMAN, K.G. Resistência de plantas daninhas a herbicidas. Disponível em: http://www.hrac-br.com.br/arquivos/ texto_resistencia_herbicidas.doc. Acesso em 7 de março de 2003.
MADSEN, K.H.; JENSEN, J.E. Weed control in glyphosate tolerant sugarbeet (Beta vulgaris L.). Weed Research, Oxford, v.35, n.2, p. 105-111.

PONCHIO, J.A.R. Resistência de Bidens pilosa aos herbicidas inibidores da enzima acetolactato synthase. 1997. 139f. Tese (Doutorado) - Escola Superior de Agricultura "Luiz de Queiroz" - Universidade de São Paulo, Piracicaba.

SEEFELDT, S.S.; JENSEN, S.E.; FUERST, E.P. Log-logistic analysis of herbicide dose-response relationship. Weed Technology, Champaign, v.9, n.1, p.218-227, 1995.

STREIBEG, L.C.; RUDEMO, M.; JENSEN, J.E. Dose response curves and statistical models. In: STREIBEG, J.C.; KUDSK, P. (Eds.). Herbicide Bioassay. Boca Raton, FL: CRC Press, 1993. p. 30-35. 